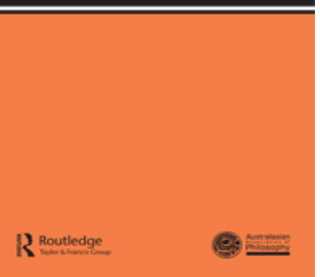

\title{
Desire and What It's Rational to Do
}

\section{Ashley Shaw}

To cite this article: Ashley Shaw (2021) Desire and What It's Rational to Do, Australasian Journal of Philosophy, 99:4, 761-775, DOI: 10.1080/00048402.2020.1822424

To link to this article: https://doi.org/10.1080/00048402.2020.1822424

\section{Published online: 21 Oct 2020.}

Submit your article to this journal

\section{Article views: 286}

Q View related articles $\square$

View Crossmark data \lceil 


\title{
Desire and What It's Rational to Do
}

\author{
Ashley Shaw \\ University College London
}

\begin{abstract}
It is often taken for granted that our desires can contribute to what it is rational for us to do. This paper examines an account of desire-the 'guise of the good' - that promises an explanation of this datum. I argue that extant guise-of-the-good accounts fail to provide an adequate explanation of how a class of desires-basic desirescontributes to practical rationality. I develop an alternative guise-of-the-good account on which basic desires attune us to our reasons for action in virtue of their biological function. This account emphasises the role of desire as part of our competence to recognise and respond to normative reasons.
\end{abstract}

ARTICLE HISTORY Received 16 November 2019; Revised 26 July 2020

KEYWORDS desire; rationality; practical rationality; evaluative judgment; reasons; guise of the good

\section{Introduction}

Many of our desires spontaneously arise without prior decision or deliberation. Such desires can contribute to what it is rational for one to do. Take, for instance, a desire to go for a stroll, a desire to eat a sweet snack, or a desire to hug a loved one. There is a distinctive kind of influence that such desires exert from the perspective of the agent. Other things being equal, it is natural to hold that these desires can rationalise corresponding intentions and actions.

However, an explanation of how such desires can rationalise actions remains elusive. This paper examines a pedigreed approach to explaining this datum - the 'guise of the good'- according to which desire involves a representation of its objects as, in some sense, normatively favoured.

The plan is as follows. Section 2 clarifies the notion of desire and practical rationality at issue, and further substantiates the intuition of rational significance. Section 3 argues that extant guise-of-the-good accounts fail to accommodate a particular class of desire or to provide a satisfactory explanation of their rational significance. Section 4 develops an alternative explanation within the spirit of the guise of the good. This account appeals to the biological function of such desires, and motivates the view that they comprise an important part of our capacity to respond to normative reasons for action. I argue that this account evades the problems that I identify for its rivals. 


\section{The Rational Significance of Desire}

Two preliminary clarifications are needed. The first concerns the relevant notion of desire at issue. I distinguish between pro-attitudes and desires, and isolate several marks of the class of desire that will be our focus. The second concerns the relevant notion of rationality at work, and clarifies the intuition concerning desire's rational significance.

\subsection{Desire}

In its broadest sense, the term 'desire' is used generically to denote any motivational state: it is synonymous with a dominant usage of the term 'pro-attitude'. This category includes a wide range of mental states including intentions, hopes, wishes, as well as transient psychological episodes like a passing urge, or a wave of anger or fear. Arguably, beliefs or judgments about what is good or valuable would qualify as desires.

However, 'desire' can also be used more narrowly to denote a proper subset of proattitudes (for example, 'desires proper' in Schueler [1995]). For clarity, I reserve the term 'desire' for this subset of pro-attitudes. Philosophers disagree over which features or functional role a pro-attitude must possess if it is to count as a desire. Some claim that desires are pro-attitudes that play a role in the production of rational goal-directed behaviour [Stalnaker 1984; Smith 1994] or of behaviour sensitive to reward-based learning [Schroeder 2004]. Others isolate affective phenomenology as essential to desires [Strawson 1994]. For present purposes, I stay neutral on this issue by accepting a substantial degree of heterogeneity within the class of desire (cf. Schroeder [2004: 162]). We can then frame the operative question as follows.

Q1 Which desires are rationally significant, and in virtue of what are those desires rationally significant?

Many working on this issue assume that there is a unique feature that explains the rational significance of every desire. However, we should not foreclose on the possibility that multiple features jointly provide different explanations of why distinct subsets of desire are rationally significant. While extant guise-of-the-good accounts are successful in explaining why some desires can rationalise action, I argue here that these explanations fail to generalise to a particular class of desires that I call basic desires.

To fasten upon basic desires, consider some canonical examples-for example, paradigmatically appetitive desires like the desire to eat when hungry or to drink when thirsty. Closely related are desires connected to bodily needs, although with more specific contents-for instance, the desire for foods with particular flavours or appearances. Other basic desires are not necessarily tied to homeostatic needs-for instance, sexual desires. However, not all basic desires have objects related to biological-function fulfilment. Humans are capable of developing more idiosyncratic basic desires ontogenetically-for instance, desires to accumulate money, to consume drugs, to visit Mars, etc.

Reference to the objects of basic desire can only take us so far. A more promising strategy will be to highlight several criterial features or 'marks' of basic desires. Without loss of generality, I consider a paradigmatic appetitive desire to eat something sweet. 
(1) Basic desires take two forms, standing and occurrent. Standing basic desires are dispositional states. A standing basic desire to eat something sweet is a dispositional state that we colloquially describe as one's having a 'sweet tooth'. Specifically, it is a disposition to undergo a psychological event or process with characteristic phenomenology (more on this in section 4) under various triggering conditions. This transient episode is the corresponding occurrent form of the basic desire to eat something sweet.

(2) Basic desires are a proper subset of intrinsic desires. As standardly formulated, the objects of intrinsic desires are wanted 'for their own sake' [Schroeder 2004: 5]. By contrast, the objects of instrumental desires are wanted as a means to some desired end. This distinction means that basic desires cannot be demarcated simply at the level of content. The motivational state that we can accurately describe as a desire for something sweet could be instrumental if it is a desire to eat something sweet because it would serve some other desired end. ${ }^{1}$

(3) Discussions of basic desire in occurrent form often focus on their distinctive aetiology which is non-volitive: that is, that they are not the product of exercises of our agency. A basic desire to eat something sweet does not arise as a result of a 'decision or deliberation'; rather, it 'simply assail[s] us' [Nagel 1970: 29] or 'come[s] upon us' [Schafer 2013: 260] under various conditions.

(4) When occurrent basic desires arise spontaneously, there is a phenomenologically familiar sense in which such desires are motivational. When they strike, such desires spur us to act. Philosophers have described this aspect by calling occurrent desires 'action-oriented' [Schapiro 2009: 230].

I stress that features (1)-(4) are characteristic features that can help us to isolate the kinds of states of interest. Ultimately, the category of basic desire will be demarcated aetiologically by appeal to underlying mechanisms that generate them (see section 4). For now, I turn to the question of the sense in which such desires can contribute to what it is rational for one to do.

\subsection{Rational Significance}

In what sense are desires rationally significant? A reasonable starting point is that evaluations of practical rationality are concerned with whether an agent's responses make sense relative to her perspective. In this respect, rationality is distinguished from correctness, where an agent $A$ 's responding in way $\phi$ in circumstance $c$ is correct if and only if the total balance of normative reasons favour $A$ 's $\phi$-ing in $c$. An action that is correct in this sense is one that we objectively ought to perform: objective oughts are 'decisive reason-implying' [Parfit 2011: 33].

To illustrate how rationality and correctness diverge, consider cases where an agent has a partial or mistaken epistemic state. Suppose that $A$ falsely believes that some amber liquid in front of her is beer when it is instead gasoline [Williams 1979]. A's rationality cannot be impugned if she were to act on her desire for beer by taking a

\footnotetext{
${ }^{1}$ My reason for saying that basic desires are a proper subset of intrinsic desires is that there can be intrinsic desires that do not exhibit a further characteristic feature that I discuss in section 3.2.1-namely, the possibility of their being recalcitrant to normative judgment.
} 
sip of the gasoline even though this is not the correct thing to do. There is an intuitive sense in which taking a sip of the liquid would be rational for her to do, given her mistaken belief that doing so would quench her thirst.

Even distinguishing rationality from correctness, there remains controversy about whether rationality requires responsiveness to apparent reasons [Sylvan 2015; Alvarez 2018; Lord 2018] or whether it is entirely a matter of compliance with certain 'structural' requirements governing combinations of attitudes [Broome 2013]. Given this controversy, I will avoid foreclosing on which notion of rationality is relevant to understanding the rational significance of desire.

Finally, it is important not to draw an overly strong conclusion from the kinds of cases considered at the outset. Suppose that one is deciding whether to have a salt or a sweet snack, when an occurrent desire for the sweet option strikes. Such a desire may not rationalise, all things considered-for example, if one were also to learn of a serious health issue, or if one had stronger competing desires. So, while a basic desire to $\phi$ may rationalise $\phi$-ing, it does so defeasibly, in the absence of countervailing conditions.

\section{Desire and the Guise of the Good}

This section considers accounts that explain desires' rational significance by appeal to their objects being under the guise of the good. I begin by clarifying the core commitment of guise-of-the-good accounts of desire. I then outline two formulations of the view, arguing that they fail to accommodate the kinds of desires discussed in section 2.1.

\subsection{The Basics}

The guise of the good can be understood as a broad thesis about the nature of rational agency as such, or as a narrower thesis about desires and their influence on rational agents. The broad thesis claims that what distinguishes the intentional actions of rational agents is that they are the product of what the subject takes to be, in some respect, normatively favoured. This thesis articulates a 'formal' constraint on rational agency [Boyle and Lavin 2010]. I will focus instead on narrower versions of the guise of the good as concerned with the nature of desires. According to this thesis, desire constitutively involves representation of its objects as normatively favoured in some respect. ${ }^{2}$ We may unpack this idea with two questions.

Q2 In what way does desire represent its objects as normatively favoured?

Q3 What is the notion of normative favouring involved?

The literature centres on two main answers to Q2. We need to clarify which representational state we look to, within the theoretical domain, as being our model of desire. The two main contenders are belief and perception, arguably states that involve representing the world as being a certain way. Cutting across this distinction is whether we think of the relevant representation as having a normative content. According to content-based formulations, a desire to $\phi$ represents the act-type $\phi$ as normatively favoured by being a representational state with the content that $\phi$-ing is $F$,

${ }^{2}$ For discussions of guise-of-the-good theories of desire, see Stampe [1987], Hawkins [2008], Schapiro [2009], Schafer [2013], and Gregory [2016]. 
where $F$ is the notion of normative favouring settled by Q3. The alternative is an attitude-based formulation, typically glossed by its proponents as the claim that a desire to $\phi$ consists of a certain kind of attitude-representing-as- $F$-in which the subject stands to the content $\phi$ (Tenenbaum [2007, 2008]; Schafer [2013]; and, for discussion, see Schroeder [2008]).

Several answers to Q3 are available. Scholastic formulations focused on goodness as the relevant way in which desire represents its objects as normatively favoured. However, the threat of seeming counterexamples involving cases of bad, evil, or whimsical desires has motivated the rise of alternatives that construe the relevant representation as one involving deontic contents [Schafer 2013] or contents about normative reasons [Gregory 2013, 2016, 2018]. This paper will not arbitrate between these answers to Q3, and the negative portion of this paper will be general enough to cover any variation in how we understand 'normative favouring'.

Now that we have a sense of the various theoretical possibilities, we can consider examples of guise-of-the-good accounts of desire in the literature that aim to explain how desires rationalise action.

\subsection{Desire as Belief about Reasons}

In a series of recent papers, Alex Gregory argues that desire is belief about normative reasons [2013, 2016, 2018]:

Desire as Belief with Normative Content (DAB). 'To desire to $\phi$ is to believe that you have normative reason to $\phi . '$ [Gregory 2016: 201].

Gregory explains the rational significance of desire by appeal to the principle that rationality requires responsiveness to one's de dicto normative beliefs (beliefs with normative content). This requirement of rationality is typically captured by what is called an 'enkratic' principle [Broome 2013], which Gregory formulates as the claim that ' $[r]$ ationality favours $\phi$-ing to the extent that you believe you have reason to $\phi$ ' [2018: 1072]. Given DAB's identification of desire with normative belief, we can explain why desiring to $\phi$ can rationalise one's $\phi$-ing, in terms of the fact that rationality favours, to some degree, your $\phi$-ing if you believe that you have reason to $\phi$.

While this account might well apply to some desires-there is, after all, a broad sense of 'desire' that might include normative beliefs-I will argue that the account is implausible when considering basic desires. Without loss of generality, I will take as an illustrative example the typical desire to eat some chocolate.

\subsubsection{Problem 1: Basic Desires Aren't Normative Beliefs}

Many philosophers have questioned whether desire necessarily involves normative beliefs. Some focus their critical attention on issues concerning the preconditions for concept possession [Velleman 1992; Hawkins 2008]. However, the characteristic way in which occurrent basic desires may be recalcitrant to normative judgment can establish this without weighing in on controversial issues about the thresholds for concept possession. Take, for instance, a desire to eat chocolate while on a diet. For such cases to be counterexamples to $\mathrm{DAB}$, they must be controlled to ensure that the subject genuinely lacks any belief that she has a reason to eat chocolate, as opposed to such a belief s rational force being outweighed by other reasons (for example, transient pleasure-based reasons). I offer this case: 
Chocolate Cake. At time $t_{1}$, Tom, a lover of chocolate, is presented with a cake. What strikes him is the cake's lavish chocolate coating with the sponge looking rather dry. Tom is struck by an occurrent desire to eat a slice of cake. At $t_{2}$, a scientist alters Tom to induce a painful reaction upon contact with the chocolate that would instantaneously neutralise any pleasure response. On the reliable scientist's testimony, Tom comes to believe that the fact the cake is coated with chocolate now counts against eating it. Nevertheless, looking at its chocolate coating, he still feels inclined to eat the cake.

It is relatively uncontroversial that a rational subject's beliefs are regulated by her view of the evidence for or against the truth of the belief (see Scanlon [1998: 20] on 'judgement-sensitivity'). So, after the scientist's intervention, Tom's subsequent judgment that the only apparent good-making feature of the cake now counts decisively against eating it should lead him to abandon the belief. This entails abandoning the desire if DAB is true. So, normative beliefs are not a necessary part of the kind of desire that Tom continues to possess.

Gregory [2016] considers a similar counterexample involving a heroin addict who wants to 'shoot up' but believes that she has no reason to do so. Gregory responds that, to the extent that this conative state is not reasons-responsive, it is not a desire but a 'primitive compulsion or drive' [ibid.: 210]. There is a danger of special pleading against those who think that Chocolate Cake constitutes a counterexample. Gregory should not deny that the appetitive inclination that Tom feels is a desire simply because it is recalcitrant to countervailing normative judgment. Moreover, it is dubious whether reflection on addiction cases can be of any help. It is far from obvious that addictions are not kinds of desires; indeed, some accounts of states of addiction involve abnormally powerful desires [Holton and Berridge 2013]. Nor is it necessary to think that Tom has an addiction to chocolate with the host of exaggerated properties of addictive states.

\subsubsection{Problem 2: DAB Over-intellectualises Rational Support}

This section argues that Gregory's explanation of how desires rationally support action is objectionably over-intellectualised.

Notice that, on his explanation, it is not the apparent reason that one believes oneself to possess, but the content that those considerations are reasons, that does the rationalising. The problem is that this makes it a necessary condition on desire's having the power to rationally support action that the subject possesses the capacity to form beliefs about normative reasons. I take this to be an unattractive consequence of the view, because it introduces an unmotivated gulf between the desires of subjects with the sophisticated capacity to form normative beliefs and those of subjects without this capacity. Many of the intuitions that led us to think that desires can rationally support action apply just as naturally to children without the capacity to think about justificatory reasons. Take young Uma who forms an occurrent desire for ice cream at a restaurant. It seems unmotivated to hold that such desires have the power to rationalise the choice of ice cream in a conceptually mature subject, yet to deny Uma's desires that same power.

\subsection{Desire and the Perceptual Analogy}

This section evaluates guise-of-the-good accounts of desire that look to perception as the model for the representational state in question. This 'turn to perception' is 
motivated by the promise of explaining how desire can be recalcitrant to normative belief, on the model of how it can perceptually appear to one that $p$ even if one believes that not- $p$ (under the Müller-Lyer illusion, for example). Two formulations of this view are discussed-content-based and attitude-based. I argue that the content-based variant faces a similar problem to $\mathrm{DAB}$, while extant versions of the attitude-based variant are explanatorily inadequate.

\subsubsection{Content-Based Perceptualism}

According to the content-based variant, we have this:

Desire as Perception, Content-Based (DPC). To desire to $\phi$ is for it to appear to one that some property $F$ or consideration $C$ pertaining to one's $\phi$-ing is a reason for one to $\phi$.

Arguably, the account of unmotivated desire given by Scanlon [1998] is a version of DPC. ${ }^{3}$ According to him, such desires involve dispositions for one's attention to be 'directed insistently toward considerations that present themselves as counting in favor of P' [ibid.: 39]. Scanlon claims to be able to accommodate the possibility of recalcitrance, analysing it as involving a 'strong and recurrent tendency to see something as a reason' contrary to a 'firm considered opinion ... that it is not such a reason' [ibid.: 40].

For this reason, I focus on extending the second objection that I raised for DAB, concerning its over-intellectualised explanation of how desires rationalise action. For it to quasi-perceptually appear to one that a consideration is a reason for action, one must exercise the concept of a reason. So, to the extent that desires rationalise in virtue of consisting of a perception with normative content that one then endorses, only the desires of those who possess the concept of a normative reason have the power to rationalise action. This introduces an unmotivated gulf between subjects who possess, and those who lack, the concept of a normative reason, despite the initial intuitions about desire's rational significance seeming to apply equally to both types of subjects.

\subsubsection{Attitude-Based Perceptualism}

Those who wish to pursue the perceptual model would do well to avoid content-based formulations. I will consider two recent attempts to develop what I have called 'attitudebased' formulations.

Schafer [2013] argues that a content-based formulation breaks the analogy with perception. When a perception that $p$ rationalises a corresponding belief, one does not perceive that it is true that $p$. Analogously, a desire to $\phi$ rationalises an intention to $\phi$ not by presenting the content that $\phi$-ing is good/ought to be done/etc. Instead, there is a 'manner in which [desires] present their content to the subject', their 'imperatival' Fregean 'force' [ibid.: 270], which presents courses of action as 'something that [one] ought to do' [ibid.: 275]. On Schafer's view, desires rationalise intentions because desires '[have] the same force and content as an intention to [ $\phi$ ]' [ibid.: 276, italics mine]. An intention to $\phi$ is 'simply an endorsement of the way [desire] already presents [ $\phi$-ing] to the subject' [ibid.: 277 , italics mine]. Similarly, Tenenbaum appeals to the idea that desires are 'prima facie' attitudes involving 'an inclination to hold a certain content good' [2008: 135]. The rational transition from desire to intention is one of

${ }^{3}$ Scanlon glosses the desire to buy a new computer as 'ha[ving] clear normative content ... that I have reason to buy a new computer' [1998: 43, italics mine]. 
endorsing a prima facie attitude in forming an 'all-out' attitude, intention. By making the relevant normative property part of the relation in which the subject stands to the content in question, we neatly evade the problem of over-intellectualising our explanation of how desires rationalise action (cf. Schroeder [2008: 123]).

The central problem for extant versions of the Attitude View is that they are too underdeveloped to provide a satisfactory explanation of how desires rationalise intention and action. The issue centres on the attitudinal relation that carries almost all of the explanatory weight - the notion of 'imperatival force' (Schafer) or inclinations to 'hold as good' (Tenenbaum). What, exactly, is this good/ought-involving relation?

Tenenbaum suggests that the relation is not merely any relation for which goodness is a correctness condition [2008: 133-4]. Rather, it is constitutively connected with goodness. Tenenbaum asks us to consider Moore-paradoxical assertions of the form 'I believe that $p$, but it is not true that $p$.' Their seeming to be paradoxical suggests that 'truth is not just a norm of correctness for belief, but that believing $\mathrm{p}$ involves holding $p$ to be true' [ibid., italics mine]. Tenenbaum extends this thought to desire, claiming that desires involve holding acts/outcomes to be good.

Yet, for all that Schafer and Tenenbaum say, this still leaves us without an account of the relation expressed by placeholder constructions like 'holding to be good' or 'presenting as ought to be done'. To draw out this point, we can probe how the views distinguish between force and content. What is the difference between standing in the presentingas-true relation to the content that $\phi$-ing is good and standing in the presenting-as-good relation to the content $\phi$ ? Extant attitudinal theories do not equip us with the resources to explain this difference. This is no trivial matter, since the distinction is central to their explanation of the rational role of desire. Without an explanation of the cash-value of the distinction, it is not clear that we have a surer grip on the idea of attitudinal force than on how desires rationalise intentions.

\subsubsection{Taking Stock}

Doxastic and perceptualist views face difficulties. While basic desire's possible recalcitrance to changes in the agent's normative beliefs favours perceptualist accounts, all content-based formulations objectionably over-intellectualise the rational import of basic desire. On the other hand, extant attitude-based formulations are not adequately explanatory. To be clear, the problem raised does not compel one to abandon attitudebased views altogether. Instead, it constitutes an invitation for those who are sympathetic to the view to articulate a clear account of what it is for a state to present content as 'ought to be done' in a way that distinguishes it from the content-based formulations. The following section takes up this task.

\section{Desire as Attunement to Reasons}

This section develops an explanation of basic desire's rational significance by appealing to the role that desires play in facilitating responsiveness to apparent reasons. The core idea is that occurrent basic desires play a role in determining our apparent reasons, because our system of basic desires constitutes a competence to recognise, and respond to, (a subset of) one's normative reasons for action.

The view will be developed in two steps. The first step will be to explain the idea of a 'reasons-sensitive' competence (section 4.1), and to motivate the suggestion that the conative system of which basic desires are a part comprise just such a reasons-sensitive 
competence (section 4.2). This requires that we attend to the nature of the conative system at the sub-personal level, the categorical basis of this competence. The second step explains the operation of this system at the personal level, and describes how basic desires shape one's apparent reasons for action, thereby affecting what it is rational for one to do.

\subsection{Desire and Reasons-Sensitive Competence}

Our system of desires, I propose, constitutes a reasons-sensitive competence. To unpack this, we need to say more about the notion of an apparent reason before explaining the idea of a reasons-sensitive competence.

Apparent reasons contribute to explaining the rationality of actions. Apparent reasons include facts of which one is aware that appear to favour certain responses. But, as many have pointed out [Parfit 2011; Sylvan 2015; Alvarez 2018], apparent reasons also include considerations that are 'merely apparent' [Parfit 2011: 35]. In the case of the factual error discussed earlier, what $A$ believes-namely, that the glass of amber liquid is beer-does not obtain, and so is not a fact that favours taking a sip. Nevertheless, given $A$ 's epistemic perspective, what she believes rationalises her taking a sip.

What are apparent reasons? Although still actively debated, I am sympathetic to understanding apparent reasons as a function of competences [Mantel 2013; Sylvan 2015; Kauppinen forthcoming]. Competences, like the skill of the archer to hit her target, are dispositions of an agent to succeed at a certain activity [Sosa 2017: 72]. A reasons-sensitive competence is a disposition to succeed in acting in response to normative reasons; specifically, 'to treat considerations like objective reasons to do $\phi$-like things only if they are objective [normative] reasons to do $\phi$-like things' [Sylvan 2015: 604]. On competence-based views, an agent's apparent reasons are states of affairs such that she is attracted to treating them as normative reasons in virtue of such reasons-sensitive competences. The view explains why $A$ acts rationally in cases of factual error: $A$ acts rationally because she competently, although incorrectly, treats what she believes as a reason.

While credible, for present purposes I maintain only a weaker claim entailed by competence-based views-namely, that some apparent reasons are a function of reasonssensitive competences. I will appeal to competences in order to explain how desires provide us with apparent reasons in a way that enables us to avoid the problems of over-intellectualism. Indeed, Sylvan's [2015] competence-based view-in particular, the concept of 'treating as a reason'-is developed explicitly to avoid an over-intellectualised account of apparent reasons.

With that in mind, the core idea to be pursued now is this:

Desire as Reasons-Sensitive Competence (DRC). The system of conation of which basic desires are a part constitutes a competence to recognise a subset of normative reasons for action.

Two clarifications are needed. First, if DRC is true, then some considerations that we take to obtain are apparent reasons for action, in virtue of our occurrent basic desires. This is neutral with respect to the substantive issue in value theory of whether normative reasons are desire-based. Following Schafer [2013], I maintain an account that remains neutral on whether desires determine what one 'objectively' ought to do or what one has normative reason to do. Second, it should be emphasised 
that our overall competence to respond rationally to reasons consists of a network of 'local' competences that, inter alia, include the kind of competence that DRC embodies [Kauppinen forthcoming]. Local competences ground a particular domain in which we are competent reason-recognisers. For instance, the competence to see that proving a certain mathematical theorem favours a certain kind of approach draws on a competence that is developmentally distinct from perceptual competences to form judgments about colour [ibid.].

\subsection{Proper Functionalism about Desire}

To make the case for DRC, it is necessary to look at the entire conative system of which basic desires are a part-in particular, the underlying desire-producing mechanisms (DPMs) that play a role in producing and regulating our standing desires and, by extension, the occurrent basic desires that we are disposed to have. ${ }^{4}$ This larger system constitutes the categorical basis or 'seat' [Sosa 2017: 191] of the reasons-sensitive competence in question. I propose a teleo-functional account of this system, and I explain how it improves on the views considered in section 3 .

\subsubsection{Force and Function}

Recall Schafer's suggestion that desire rationalises intention because both share imperatival' force. In this way, he suggests that 'desires play the role of standard inputs into our processes of practical reasoning[, just as] perceptual experiences play the role of standard inputs into our processes of theoretical reasoning' [2013: 264, italics mine].

There is a natural way to capture Schafer's idea within a functionalist account of desire. We should think of occurrent basic desires as having a functional role that is isomorphic with that of perceptual experiences. ${ }^{5}$ Both are standard inputs, not by virtue of being a reliable cause of intention and belief, respectively, but due to their having a nature such as to initiate intention and belief formation, respectively. I advocate following the tradition that appeals to functions [Millikan 1984; Burge 2003; Graham 2012]. Just as perceptions are 'standard' inputs into processes that lead to belief formation in virtue of sharing a core function - to represent veridically [Burge 2003, 2020] - occurrent basic desires are standard inputs into processes that lead to intention in virtue of sharing a core function with intention. The proposal is that we cash out parity of 'force' in terms of coordination of function. ${ }^{6}$

The general notion of function that I employ is aetiological: roughly, a token $x$ of type $X$ has an aetiological function to $\psi$ if ancestral $X$ 's having previously $\psi$-ed explains why $x$ now exists - for example, by explaining its replication and proliferation [Wright 1973; Millikan 1984]. For biological phenomena, this explanation is one of the effect's contribution to fitness under natural selection. Following Millikan, we may call this a device's biological or proper function.

It is important to note that functional items may possess distinct functions along distinct axes. For example, the human tongue possesses distinct functions along the

\footnotetext{
${ }^{4}$ My focus on desire-producing mechanisms is inspired by important insights developed by Stampe [1987].

${ }^{5}$ Obviously, by 'isomorphic', I do not mean that occurrent basic desires have an identical functional role with (e.g. visual) perceptual experiences; I mean only that they have a functional role that mirrors each other in virtue of being coordinated by some overarching vertical function (more on this shortly).

${ }^{6}$ This will require shifting to a variant of the functionalist view on which mental state types are individuated, not by their causal roles, but by their teleofunctions [Sober 1985].
} 
'horizontal' axis to enable the performance of activities like talking, tasting, swallowing, etc. [Graham 2012: 458]. A function on the vertical axis is one that contributes to the performance of some function on the horizontal axis. To illustrate, the tongue has the function of engaging in a particular backward rolling motion in coordination with the soft palate to assist in discharging its function of swallowing food. Similarly, we can talk of horizontal and vertical functions of the conative system to which basic desires belong.

\subsubsection{Functions: Horizontal and Vertical}

With this in mind, I want to start by considering an overarching horizontal function shared by basic desire-producing mechanisms (DPMs), standing basic desires, and occurrent basic desires.

Very plausibly, what explains the existence of our DPMs and, by extension, our standing and occurrent desires is their having historically motivated subjects to do what is conducive to survival and reproduction. We can sharpen this thought by identifying core biological functions of whole organisms, such as eating, drinking, locomoting, foraging, fleeing, mating, etc., all of which are keys to explaining reproductive success. A chief horizontal biological function of DPMs is to motivate the organism to realise outcomes that conduce to the fulfilment of these core biological functions under normal conditions.

Let us turn now to vertical functions. DPMs perform their biological function by performing a key vertical function: to produce and regulate standing desires in a manner that conduces to the fulfilment of core biological functions. To see how, note that, for functional items in general, there is an aetiological explanation of how producing a certain effect $\psi$ contributed to its proliferation. Millikan calls these 'Normal' (capitalised) explanations. For a functional item, a Normal explanation specifies the following:

- Normal Functioning: how the item operated to produce the effect for which it was selected,

- Normal Constitution: the internal structure of the item when functioning Normally, and

- Normal Conditions: conditions that obtain when it produced the effect for which it was selected.

There is a range of accounts in the literature of the Normal functioning and constitution of our DPMs. To take one, Tim Schroeder suggests that DPMs produce and regulate our desires as a function of an agent's stock of standing desires in a process of contingencybased learning [2004: 66]. I highlight two features of Schroeder's view. First, we have innate standing desires for objects that are reliably conducive to the fulfilment of core biological functions - for example, desires for food, warmth, etc. Second, DPMs produce novel desires based on their reward value, calculated as a function of the agent's motivational priors [ibid.: 147]. In this way, we can see how DPMs produce and regulate desires that will retain an indirect connection to the fulfilment of core biological functions. ${ }^{7}$

Let us now focus on standing basic desires. As products of DPMs, standing desires have the vertical function of interfacing with the subject's cognitive or sensory capacities

\footnotetext{
${ }^{7}$ Reference to Schroeder's view is merely illustrative. For present purposes, we can be neutral on the fine detail of this process, provided that there is some mode of operation by which DPMs produce and regulate standing desires to be good-conducive under Normal conditions. The same points hold for rivals to Schroeder's view (e.g. Butlin [2017]).
} 
to bring about occurrent basic desires. The details of the kinds of conditions under which standing desires give rise to occurrent desires is an empirical matter, and these details depend on the nature of the standing desire in question. For example, while appetitive standing desires interface, inter alia, with the kinds of sensory capacities required for maintaining homeostasis, other standing desires (for sex, for instance) will not. Given how standing desires are regulated by DPMs when functioning and constituted Normally, it should be clear how the fulfilment of this vertical function serves to advance their horizontal biological function so as to motivate the agent to bring about outcomes that satisfy core biological functions.

The final and most important piece in motivating DRC involves explicating the Normal functioning of occurrent basic desires. Occurrent basic desires, I claim, have the function of attuning us to reasons. To illustrate what this involves, consider passing through a food market when a punnet of delicious, red, and plump strawberries catches your eye. At that moment, you experience an attraction to eat those strawberries.

There are two elements involved in this that should be phenomenologically familiar -an attentional component and a motivational one.

The attentional component involves a disposition to have one's attention exogenously drawn to some salient feature $F$ of an outcome that one represents [Scanlon 1998: 34]. For example, when one has the occurrent desire to eat strawberries, one is disposed to have one's attention continually drawn to features such as the plump red flesh of the strawberries that one perceives, or to memories of the flavour of the strawberries.

The motivational component of an occurrent desire involves a 'non-alienating' [Schroeder 2007: 156] felt impulse to treat the item's having property $F$ as favouring a certain response - that is, as a reason for a certain response $\phi$. To treat an attractant's having property $F$ as a reason to $\phi$ is for the representation of the attractant's being $F$ to influence practical reasoning by assigning some weight to the option of $\phi$-ing. For example, in virtue of one's desire to eat strawberries, one feels an impulse to treat the fact that the strawberries have the appearance that they do as contributing some weight to $\phi$-ing in the course of determining what it is that one should do.

Let us now bring together all of these elements.

According to DRC, our conative system with its stock of standing desires comprises a reasons-sensitive competence-a disposition to respond to a subset of one's normative reasons. The relevant reasons are prudential. Here I assume that there are prudential reasons for agents to fulfil core biological functions (to eat, drink, etc.). Our desire-regulating/producing mechanisms (DPMs) constitute the basis of a competence to respond to such reasons because they have the function of regulating an agent's motivation in prudentially good-conducive ways.

DPMs motivate action by producing standing desires for outcomes that are, to varying degrees, related to the fulfilment of core biological functions. Under certain triggering conditions, standing desires become occurrent. Occurrent basic desires are manifestations of the reasons-sensitive competence, just as the archer's shot is the manifestation of the archer's skill. An occurrent basic desire to $\phi$ sustains an attraction to treat certain features $F$ of outcomes that we represent in perception or cognition as $a$ reason to $\phi$. I suggest that this competent attraction to treat some feature $F$ as a reason is nothing short of one's being presented with an apparent reason for action. To have an occurrent basic desire, then, is a way of being attuned to one's reasons. 


\subsection{How Do Basic Desires Contribute to What it Is Rational to Do?}

We are now in a position to answer our central question head-on. To be in the grip of an occurrent basic desire is for features within one's perspective to appear as apparent reasons for action. In acting on a desire, one acts for the reason to which the desire attunes one. Desires contribute to what it is rational to do, by affecting an agent's perspective on her apparent reasons for action.

How does the view here improve on the problems raised for extant guise-of-the-good accounts of basic desire?

I will start with the problem of over-intellectualisation. On the account developed here, basic desires are not beliefs about one's location in the space of reasons. When one responds to a basic desire to $\phi$, one simply represents the desideratum as having features that one is attracted to treating as a reason. Following Sylvan [2015: 601-2], 'to treat $\mathrm{P}$ like an objective normative reason to $\phi$ is to be disposed to respond to the appearance that $\mathrm{P}$ in ... the ways that would be favoured if $\mathrm{P}$ were an objective normative reason to $\phi$.' When one responds to an occurrent basic desire to eat strawberries, for example, one's (apparent) reasons for eating the strawberries are facts like the strawberries' being plump and red, and not the fact that these properties of the strawberries constitute reasons for one to eat them.

Moreover, we have explained how attitude-based perceptualist accounts may employ the idea of coordination of function. Perceptions involve a presentation of their objects 'as true' in the sense that they are states that have the function to represent veridically. Analogously, basic desires involve a presentation of their objects as normatively favoured, in the sense that they are states with the function to produce desires for outcomes that are normatively favoured. Both are 'standard' inputs to belief- and intention-forming processes, respectively, in virtue of sharing the relevant overarching functions with those processes.

I end this section with a clarification concerning the conditions under which desires rationalise action. One might object that my view objectionably lowers the bar for rational responsiveness because it misclassifies non-rational responses to a basic desire as rational. For example, one could absent-mindedly act on a desire for coffee, competently treating relevant features of one's perceived environment as a reason to act in a certain way. This objection, however, fails to account for an important qualification. Desires defeasibly rationalise actions only given certain enabling conditionsspecifically, when one is suitably sensitive to conditions that would diminish reasons that there are to pursue the desired course of action. Here there is parity with visual perception, which rationalises perceptual judgments against certain enabling conditionsfor instance, causal sensitivity to ambient lighting conditions.

\section{Conclusion}

This paper has focused on how to explain the simple thought that occurrent basic desires are capable of rationalising intention and action.

Extant guise-of-the-good accounts face one of two problems: either they cannot explain the recalcitrance of occurrent basic desires to normative evaluations, or they over-intellectualise how basic desires rationalise action. On the view that I defend, our desire-producing mechanisms comprise part of our competence to recognise and respond to normative reasons in virtue of their biological function. Occurrent basic 
desires, I argue, are manifestations of this reasons-sensitive competence, and play a role in providing one with apparent reasons for action. I argued that my view avoids the problems facing rival accounts. ${ }^{8}$

\section{Disclosure Statement}

No potential conflict of interest was reported by the author.

\section{Funding}

This research was funded by an AHRC Doctoral Research Studentship.

\section{References}

Alvarez, Maria 2018. Reasons for Action, Acting for Reasons, and Rationality, Synthese 195/8: 3293310.

Boyle, Matthew and Douglas Lavin 2010. Goodness and Desire, in Desire, Practical Reason, and the Good, ed. Sergio Tenenbaum, New York: Oxford University Press: 161-201.

Broome, John 2013. Rationality Through Reasoning, Chichester: Wiley-Blackwell.

Burge, Tyler 2003. Perceptual Entitlement, Philosophy and Phenomenological Research 67/3: 503-48.

Burge, Tyler 2020. Entitlement: The Basis for Empirical Warrant, in Epistemic Entitlement, ed. Peter J. Graham and Nikolaj J.L.L. Pedersen, Oxford: Oxford University Press: 37-142.

Butlin, Patrick 2017. Why Hunger Is Not a Desire, Review of Philosophy and Psychology 8/3: 617-35.

Graham, Peter J. 2012. Epistemic Entitlement, Noûs 46/3: 449-82.

Gregory, Alex 2013. The Guise of Reasons, American Philosophical Quarterly 50/1: 63-72.

Gregory, Alex 2016. Might Desires Be Beliefs About Normative Reasons for Action? in The Nature of Desire, ed. Federico Lauria and Julien A. Deonna, New York: Oxford University Press: 201-18.

Gregory, Alex 2018. Why Do Desires Rationalize Actions? Ergo 5/40:1061-81.

Hawkins, Jennifer 2008. Desiring the Bad Under the Guise of the Good, The Philosophical Quarterly 58/ 231: 244-64.

Holton, Richard, and Kent Berridge 2013. Addiction Between Compulsion and Choice, in Addiction and Self-Control: Perspectives from Philosophy, Psychology, and Neuroscience, ed. Neil Levy, New York: Oxford University Press: 239-68.

Kauppinen, Antti forthcoming. Rationality as the Rule of Reason, Noûs.

Lord, Errol 2018. The Importance of Being Rational, Oxford: Oxford University Press.

Mantel, Susanne 2013. Acting for Reasons, Apt Action, and Knowledge, Synthese 190/17: 3865-88.

Millikan, Ruth. Garrett 1984. Language, Thought, and Other Biological Categories: New Foundations for Realism, Cambridge, MA: The MIT Press.

Nagel, Thomas 1970. The Possibility of Altruism, Princeton: Princeton University Press.

Parfit, Derek 2011. On What Matters, Oxford: Oxford University Press.

Scanlon, Thomas 1998. What We Owe to Each Other, Cambridge, MA: Harvard University Press.

Schafer, Karl 2013. Perception and the Rational Force of Desire, The Journal of Philosophy 110/5: 258-81.

Schapiro, Tamar 2009. The Nature of Inclination, Ethics 119/2: 229-56.

Schroeder, Mark 2007. Slaves of the Passions, Oxford: Oxford University Press.

Schroeder, Mark 2008. How Does the Good Appear to Us? Social Theory and Practice 34/1: 119-30.

Schroeder, Tim 2004. Three Faces of Desire, Oxford: Oxford University Press.

Schueler, G.F. 1995. Desire: Its Role in Practical Reason and the Explanation of Action, Cambridge, MA:

The MIT Press.

Smith, Michael 1994. The Moral Problem, Oxford: Blackwell.

Sober, Elliott 1985. Panglossian Functionalism and the Philosophy of Mind, Synthese 64/2: 165-93.

Sosa, Ernest 2017. Epistemology, Princeton: Princeton University Press.

${ }^{8}$ For comments and helpful discussion, thanks to Johannes Brandl, Alex Grzankowski, Poppy Mankowitz, Lucy O'Brien, Johannes Roessler, Richard Rowland, two anonymous reviewers, and the editors of this journal. 
Stalnaker, Robert 1984. Inquiry, Cambridge, MA: The MIT Press.

Stampe, Dennis W 1987. The Authority of Desire, The Philosophical Review 96/3: 335-81.

Strawson, Galen 1994. Mental Reality, Cambridge, MA: The MIT Press.

Sylvan, Kurt 2015. What Apparent Reasons Appear to Be, Philosophical Studies 172/3: 587-606.

Tenenbaum, Sergio 2007. Appearances of the Good: An Essay on the Nature of Practical Reason, Cambridge: Cambridge University Press.

Tenenbaum, Sergio 2008. Appearing Good: A Reply to Schroeder, Social Theory and Practice 34/1: 131-38. Velleman, J. David 1992. The Guise of the Good, Noûs 26/1: 3-26.

Williams, Bernard 1979. Internal and External Reasons, in Rational Action: Studies in Philosophy and Social Science, ed. Ross Harrison, Cambridge: Cambridge University Press: 17-28.

Wright, Larry 1973. Functions, The Philosophical Review 82/2: 139-68. 